\title{
Relapsing polychondritis - analysis of symptoms and criteria
}

\author{
Beata Maciążek-Chyra ${ }^{1}$, Magdalena Szmyrka ${ }^{1,2}$, Marta Skoczyńska ${ }^{1,2}$, Renata Sokolik ${ }^{1,2}$, \\ Joanna Lasocka², Piotr Wiland ${ }^{1,2}$ \\ ${ }^{1}$ Clinic of Rheumatology and Internal Medicine, Wrocław University Hospital, Poland \\ ${ }^{2}$ Department and Clinic of Rheumatology and Internal Medicine, Wrocław Medical University, Poland
}

\begin{abstract}
Objectives: Relapsing polychondritis (RP) is a rare disease characterised by recurrent inflammation of the cartilaginous structures and proteoglycan-rich organs. The aim of this case series study is to share the 10-year clinical experience of our department in diagnosing RP patients in the context of data from available published studies.

Material and methods: A retrospective case analysis of 10 patients with symptoms of RP, hospitalised at the Department of Rheumatology and Internal Diseases of Wroctaw University Hospital between January 2008 and December 2018.

Results: Nine out of 10 patients fulfilled at least one of the three sets of the diagnostic criteria. The mean age ( \pm standard deviation) at diagnosis was $54.4 \pm 13.3$ years and ranged from 32 to 73 years. The symptoms suggestive of the RP diagnosis were mainly inflammation of the pinna (in $80 \%$ of patients) and laryngeal stenosis (in 20\% of patients). The mean age at which initial symptoms were observed was $52.3 \pm 12.0$ years and ranged from 31 to 69 years. Auricular chondritis was the first manifestation of the disease in $40 \%$ of cases (two women and two men) laryngeal chondritis in $20 \%$, nasal chondritis in $10 \%$, and bronchial stenosis in 10\%. Other initial symptoms were polyarthritis, which was present in $10 \%$ of cases (male) and general symptoms observed in $10 \%$.

Conclusions: A thorough analysis of the entire medical history with specific questions about the occurrence of the manifestations of the disease in the past leads to the diagnosis of RP. The RP also should be considered in differential diagnosis of respiratory track narrowings. It is very useful to apply the three sets of criteria simultaneously in the diagnostic process.
\end{abstract}

Key words: symptoms, diagnostic criteria, relapsing polychondritis.

\section{Introduction}

Relapsing polychondritis (RP) is a rare, clinically heterogeneous, multi-systemic inflammatory disease characterised by recurrent inflammation of the cartilaginous structures and proteoglycan-rich organs. It affects primarily the cartilages of the ear, nose, larynx, tracheobronchial tree, and ribs, but the inflammatory process may damage also connective tissue components of the heart, large vessels (especially the aorta), eyes, inner ear, skin, joints, kidneys, and other organs. Clinical manifestations vary from isolated auricular chondritis to life-threatening systemic features. Red swollen pinna is the most recognised symptom of RP, while other clinical manifestations are not as typical. The course of the disease consists of recurrent acute and painful inflammation in different organs followed by asymptomatic periods with the silently ongoing inflammatory process. Relapsing polychondritis leads to progressive degeneration of cartilaginous structure and connective tissue, which may cause serious complications such as airway collapse or obstruction, deafness, loss of vision, aortic and other large vessel aneurysms, cardiac arrhythmia, heart failure, or renal insufficiency [1-3].

Relapsing polychondritis occurs most frequently between the ages of 40 and 60 years. Data on RP inci-

Address for correspondence:

Beata Maciążek-Chyra, Department and Clinic of Rheumatology and Internal Diseases, University Hospital in Wrocław, 213 Borowska St., 50-556 Wrocław, Poland, e-mail: bmchyra@gmail.com

Submitted: 11.02.2019; Accepted: 19.02.2019 
dence and prevalence comes mainly from national population-based studies. The incidence of RP estimated in a study performed recently in Hungary was about two per million person-years, which is comparable to the incidence in the US [4]. In Hungary, the overall 10-year survival was good (75-88.3\%) and comparable to that of the general population, which the authors attribute to early diagnosis. The distribution of incidences across regions may be suggestive of sunlight exposure and arsenic drinking water pollution as possible environmental triggers of RP. A high prevalence (56\%) of other autoimmune conditions was found among the Hungarian RP patients, with Sjögren syndrome as the most common concomitant autoimmune disease [4, 5].

Although, comparing to Hungary, the incidence of the disease in UK was found to be much lower (0.71 per million person-years), the standardised mortality ratio was over twice as high as in the UK general population (2.16, 95\% Cl: 1.24-3.51, $p<0.01)$, with respiratory tract disease, heart disease, and cancer as the most frequent causes of death. The mean age at diagnosis was 55 years for men and 51 years for women, while the period from first symptoms to the diagnosis was on average 1.9 years [6]. At present, the population-based studies concerning RP are scarce. No such study has been performed among the Polish population as of today.

In 1976, McAdam et al. [7] published a prospective study of 23 patients and created the first set of diagnostic criteria. In order to establish the diagnosis, at least three symptoms such as bilateral auricular chondritis, nasal chondritis, nonerosive seronegative inflammatory polyarthritis, ocular inflammation, tracheal or laryngeal cartilages' inflammation, and audio-vestibular dysfunction had to be present.

In 1979, Damiani et Levine [8] introduced the modified McAdam's criteria, which included histological changes and response to treatment. The diagnosis could be made three-way: either based on McAdam's criteria with no histological tests necessary; in the presence of at least one McAdam's sign accompanied by typical histologic changes; or in the presence of chondritis in at least two different sites and a good treatment response [8].

In 1986, Michet et al. [9] proposed the most recent set of criteria, once more based solely on symptoms. In order to meet the criteria, a patient has to present either with cartilage inflammation in at least two locations, or with a singular-site chondritis accompanied by at least two of the following symptoms: seronegative arthritis, ocular inflammation, hearing loss, and/or vestibular dysfunction [9]. Three sets of diagnostic criteria for RP are presented in Table I.

Relapsing polychondritis poses a diagnostic challenge due to its rarity of occurrence, wide variety of clinical manifestations, and lack of validated criteria. The aim of this study is to compare the clinical picture in patients with RP based on the experience of one centre, as well as reference to the available literature.

\section{Material and methods}

A retrospective case analysis of 10 patients (six women and four men) with symptoms of RP, hospitalised at the Department of Rheumatology and Internal Diseases of Wrocław University Hospital between January 2008 and December 2018, was carried out.

Table I. Three sets of diagnostic criteria for relapsing polychondritis

\begin{tabular}{|c|c|c|c|}
\hline & McAdam et al. (1976) & Damiani et al. (1979) & Michet et al. (1986) \\
\hline \multirow[t]{4}{*}{ Symptoms } & \multirow{4}{*}{$\begin{array}{c}\text { Bilateral auricular } \\
\text { chondritis } \\
\text { Nasal chondritis } \\
\text { Respiratory tract } \\
\text { chondritis } \\
\text { Non-erosive seronegative } \\
\text { polyarthritis } \\
\text { Ocular inflammation } \\
\text { Audiovestibular damage }\end{array}$} & \multirow{2}{*}{$\begin{array}{c}\text { A criteria: } \\
\text { Bilateral auricular chondritis } \\
\text { Nasal cartilage inflammation } \\
\text { Respiratory tract chondritis } \\
\text { Non-erosive seronegative polyarthritis } \\
\text { Ocular inflammation } \\
\text { Audiovestibular damage }\end{array}$} & $\begin{array}{c}\text { A criteria: } \\
\text { Auricular cartilage inflammation } \\
\text { Nasal cartilage inflammation } \\
\text { Laryngotracheal cartilage } \\
\text { inflammation }\end{array}$ \\
\hline & & & $\begin{array}{c}\text { B criteria: } \\
\text { Seronegative arthritis } \\
\text { Ocular inflammation } \\
\text { Hearing loss } \\
\text { Vestibular dysfunction }\end{array}$ \\
\hline & & $\begin{array}{c}\text { B criterion: } \\
\text { Histological confirmation }\end{array}$ & \\
\hline & & $\begin{array}{l}\text { C criterion: } \\
\text { Positive response to corticosteroids or } \\
\text { dapsone }\end{array}$ & \\
\hline Required criteria & $\geq 3$ & $\begin{array}{l}\geq 3(A) \text { or } \geq 1(A) \text { and }(B) \\
\text { or } \geq 2(A) \text { criteria and }(C)\end{array}$ & $\geq 2(\mathrm{~A})$ or $\geq 1(\mathrm{~A})$ and $2(\mathrm{~B})$ \\
\hline
\end{tabular}


Table II. Case analysis of diagnostic criteria fulfilment

\begin{tabular}{|lcccccccccc|}
\hline Case & I & II & III & IV & V & VI & VII & VIII & IX & X \\
\hline Fulfilment of criteria according to McAdam et al. & Yes & No & Yes & No & Yes & No & Yes & No & No & Yes \\
\hline The number of present criteria according to McAdam et al. & 3 & 2 & 4 & 2 & 5 & 2 & 6 & 1 & 1 & 4 \\
\hline Fulfilment of criteria according to Michet et al. & Yes & Yes & Yes & Yes & Yes & Yes & Yes & No & No & Yes \\
\hline The number of present A criteria & 2 & 2 & 2 & 2 & 3 & 2 & 3 & 1 & 1 & 1 \\
\hline The number of present B criteria & 0 & 0 & 2 & 0 & 1 & 0 & 4 & 0 & 0 & 2 \\
\hline Fulfilment of criteria according to Damiani et al. & Yes & Yes & Yes & No & Yes & Yes & Yes & Yes & No & Yes \\
\hline 3 McAdam's criteria present & Yes & No & Yes & No & Yes & No & Yes & No & No & Yes \\
\hline 1 McAdam's criterion and positive histological biopsy & NA & Yes & Yes & NA & NA & Yes & NA & Yes & No & NA \\
\hline $\begin{array}{l}\text { 2 McAdam's criteria and positive response to } \\
\text { corticosteroids or dapsone }\end{array}$ & Yes & Yes & Yes & No & Yes & Yes & NA & No & NA & Yes \\
\hline
\end{tabular}

NA - not applicable

All of them were of Caucasian origin, $n=9$ were Polish and $n=1$ was French. The average age at the onset of the first symptoms in our group was 53.2 years. The female to male ratio was $3: 2$. The clinical features, including first symptoms, age of onset, time from onset to diagnosis, and laboratory findings at first hospitalisation at our Department were analysed. Diagnoses were verified according to the three sets of criteria (characterised by Damiani and Levine, Michet, and McAdam, respectively) [7-9].

\section{Results}

The diagnosis according to McAdam's criteria was confirmed in five patients (50\%). Both Michet's and Damiani and Levine's sets of criteria were fulfilled in eight cases (80\%). Nine out of 10 patients fulfilled at least one of the three sets of criteria. One patient did not fulfil any set of criteria, but the auricular inflammation improvement after corticosteroid treatment was typical for RP. This case was classified as a probable first episode of RP that required further observation. Analysis of how each patient fulfilled different diagnostic criteria is presented in Table II.

The mean age ( \pm standard deviation) at diagnosis was $54.4 \pm 13.3$ years and ranged from 32 to 73 years. It was lower in the group of men (on average 53.2 years) compared to women (on average 55 years). The symptoms suggestive of the RP diagnosis were mainly inflammation of the pinna (in $80 \%$ of patients) and laryngeal stenosis (in $20 \%$ of patients).

The mean age when initial symptoms were observed was $52.3 \pm 12.0$ years and ranged from 31 to 69 years. Auricular chondritis was the first manifestation of the disease in $40 \%$ of cases $(n=4)$, laryngeal chondritis in $20 \%(n=2)$, nasal chondritis in 10\% $(n=1)$, and bronchial stenosis in $10 \%(n=1)$. Other initial symptoms were polyarthritis that was present in $10 \%$ of cases and general symptoms observed in 10\%. The latter are common for many different disorders and were established as first signs of RP only on retrospective analysis. In two cases polyarthritis and general symptoms emerged as the first manifestation, and the suggestion of the diagnosis of RP was made after the occurrence of redness and oedema of the pinna.

Comparative characteristics of the examined patients in terms of age, time of diagnosis, and clinical symptoms are presented in Table III.

Auricular chondritis was the most common clinical manifestation in our case series. It occurred in 8/9 patients (88.8\%) with a confirmed diagnosis and in one patient suspected for RP. The average age at the onset of auricular chondritis was $52.3 \pm 11.89$ years and ranged from 34 to 69 years. The time between the onset of this sign and the diagnosis of RP was between two and 34 months, on average 11 months. One out of nine patients developed inflammation of the pinna after the diagnosis of RP (11.1\%). Only in 1 out of 9 patients (11.1\%) no auricular chondritis was observed. An example of red ear in one of our patients is shown in Figure 1.

The second most frequently affected organ in our case series was the nose cartilage (7/9 patients, $77.7 \%$ ). Nasal chondritis turned out to be less characteristic for RP. Patients reported the feeling of fullness of the nasal bridge, and tenderness or pain at the base of the nose. Only one patient suffered from chronic nasal mucosal discharge. Permanent destruction of the nasal cartilage with a characteristic saddle-nose deformity was observed also in one case and occurred after six years from the onset of the disease.

Respiratory tract chondritis involved the larynx (4/9 patients, $44.4 \%$ ), the trachea (3/9 patients, 33.3\%), and bronchi (3/9 patients, 33.3\%) manifesting as dry cough, dyspnoea, and hoarseness. Total damage to the larynge- 
Table III. Characteristic of first and diagnostically crucial symptoms along with age at the emergence of first and crucial manifestations and delay of diagnosis in the studied cases

\begin{tabular}{|c|c|c|c|c|c|c|c|c|c|c|}
\hline Case & I & II & III & IV & V & VI & VII & VIII & IX & $x$ \\
\hline Gender & Female & Female & Male & Female & Female & Female & Female & Male & Male & Male \\
\hline $\begin{array}{l}\text { The first } \\
\text { symptom }\end{array}$ & $\begin{array}{l}\text { Bronchial } \\
\text { stenosis }\end{array}$ & $\begin{array}{c}\text { Nasal } \\
\text { chondritis }\end{array}$ & $\begin{array}{c}\text { General } \\
\text { symptoms }\end{array}$ & $\begin{array}{l}\text { Laryngeal } \\
\text { stenosis }\end{array}$ & Red ear & Red ear & $\begin{array}{l}\text { Laryngeal } \\
\text { stenosis }\end{array}$ & Red ear & Red ear & Arthritis \\
\hline $\begin{array}{l}\text { The } \\
\text { diagnostically } \\
\text { crucial symptom }\end{array}$ & Red ear & Red ear & Red ear & $\begin{array}{l}\text { Laryngeal } \\
\text { stenosis }\end{array}$ & Red ear & Red ear & $\begin{array}{l}\text { Laryngeal } \\
\text { stenosis }\end{array}$ & Red ear & Red ear & Red ear \\
\hline $\begin{array}{l}\text { Age at the } \\
\text { emergence } \\
\text { of the first } \\
\text { symptom }\end{array}$ & $\begin{array}{c}53 \\
\text { years }\end{array}$ & $\begin{array}{c}52 \\
\text { years }\end{array}$ & $\begin{array}{c}58 \\
\text { years }\end{array}$ & $\begin{array}{c}69 \\
\text { years }\end{array}$ & $\begin{array}{c}55 \\
\text { years }\end{array}$ & $\begin{array}{c}55 \\
\text { years }\end{array}$ & $\begin{array}{c}31 \\
\text { years }\end{array}$ & $\begin{array}{c}37 \\
\text { years }\end{array}$ & $\begin{array}{c}45 \\
\text { years }\end{array}$ & $\begin{array}{c}68 \\
\text { years }\end{array}$ \\
\hline $\begin{array}{l}\text { Age at the } \\
\text { diagnosis }\end{array}$ & $\begin{array}{c}58 \\
\text { years }\end{array}$ & $\begin{array}{c}53 \\
\text { years }\end{array}$ & $\begin{array}{c}59 \\
\text { years }\end{array}$ & $\begin{array}{c}73 \\
\text { years }\end{array}$ & $\begin{array}{c}57 \\
\text { years }\end{array}$ & $\begin{array}{c}58 \\
\text { years }\end{array}$ & $\begin{array}{c}32 \\
\text { years }\end{array}$ & $\begin{array}{c}37 \\
\text { years }\end{array}$ & $\begin{array}{l}45 \text { years } \\
\text { (RP highly } \\
\text { probable) }\end{array}$ & $\begin{array}{c}73 \\
\text { years }\end{array}$ \\
\hline $\begin{array}{l}\text { Time from the } \\
\text { first symptom } \\
\text { to the diagnosis }\end{array}$ & $\begin{array}{c}58 \\
\text { months }\end{array}$ & $\begin{array}{c}9 \\
\text { months }\end{array}$ & $\begin{array}{c}6 \\
\text { months }\end{array}$ & $\begin{array}{c}41 \\
\text { months }\end{array}$ & $\begin{array}{c}8 \\
\text { months }\end{array}$ & $\begin{array}{c}21 \\
\text { months }\end{array}$ & $\begin{array}{c}15 \\
\text { months }\end{array}$ & $\begin{array}{c}4 \\
\text { months }\end{array}$ & $\begin{array}{c}2 \\
\text { months }\end{array}$ & $\begin{array}{c}48 \\
\text { months }\end{array}$ \\
\hline $\begin{array}{l}\text { Time from the } \\
\text { crucial symptom } \\
\text { to the diagnosis }\end{array}$ & $\begin{array}{c}34 \\
\text { months }\end{array}$ & $\begin{array}{c}2 \\
\text { months }\end{array}$ & $\begin{array}{c}2 \\
\text { months }\end{array}$ & $\begin{array}{c}41 \\
\text { months }\end{array}$ & $\begin{array}{c}8 \\
\text { months }\end{array}$ & $\begin{array}{c}21 \\
\text { months }\end{array}$ & $\begin{array}{c}15 \\
\text { months }\end{array}$ & $\begin{array}{c}4 \\
\text { months }\end{array}$ & $\begin{array}{l}\text { Diagnosis } \\
\text { not yet } \\
\text { confirmed }\end{array}$ & $\begin{array}{c}15 \\
\text { months }\end{array}$ \\
\hline
\end{tabular}

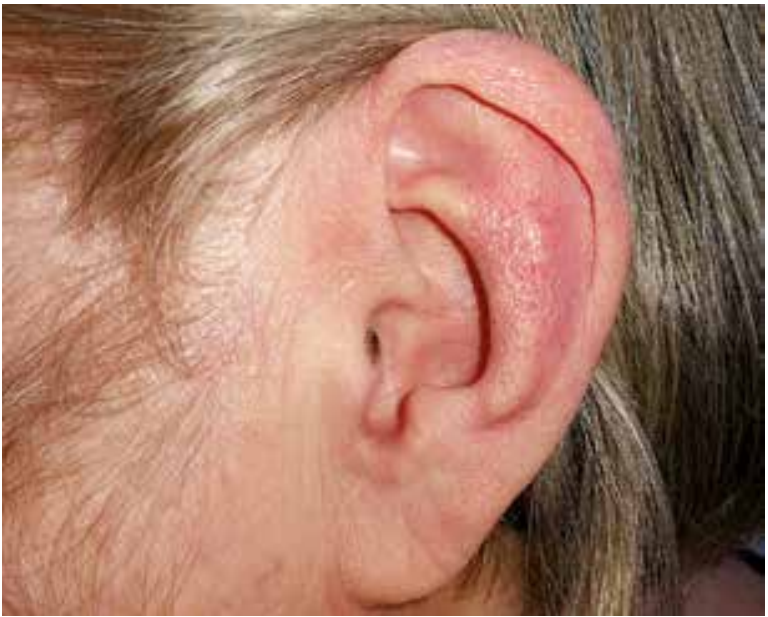

Fig. 1. Inflammation of pinna.

al cartilage presented in two female patients (22.2\%) as life-threatening stenosis with respiratory failure requiring tracheotomy. The same patients also showed the presence of tracheal involvement. The narrowing of the trachea and intermediary right bronchi was diagnosed as the cause of a chronic dry cough in one case (11.1\%).

Cardiovascular abnormalities were found in five patients (55.5\%). They included valve insufficiency $(n=3)$, dilatation of the ascending thoracic aorta $(n=1)$ and arrhythmia $(n=1)$ which required pacemaker implantation. The patient diagnosed with arrhythmia had also

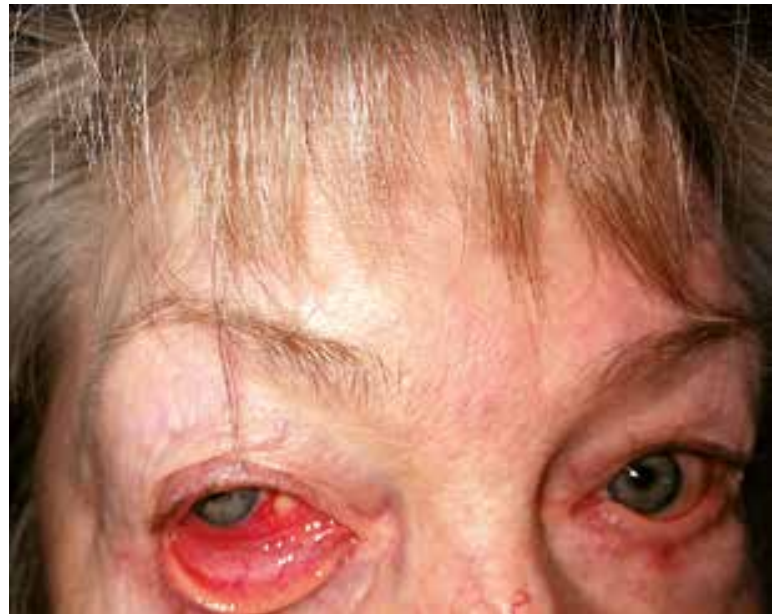

Fig. 2. Episcleritis.

aneurysms of iliac arteries, which were discovered in the course of the diagnostic process, and it was a reason for stent-graft implantation.

Arthritis was present in four cases (44.4\%). Other manifestations included ocular involvement (33.3\%) as: episcleritis $(n=1)$ (Fig. 2$)$ and scleritis $(n=2)$, hearing loss $(22 \%, n=2)$, vestibular syndrome $(n=1)$, renal involvement $(n=1)$, costal chondritis $(n=1)$, and clinically significant anaemia $(n=2)$. In Table IV disease manifestations in individual cases at the time of first hospitalisation are presented. 


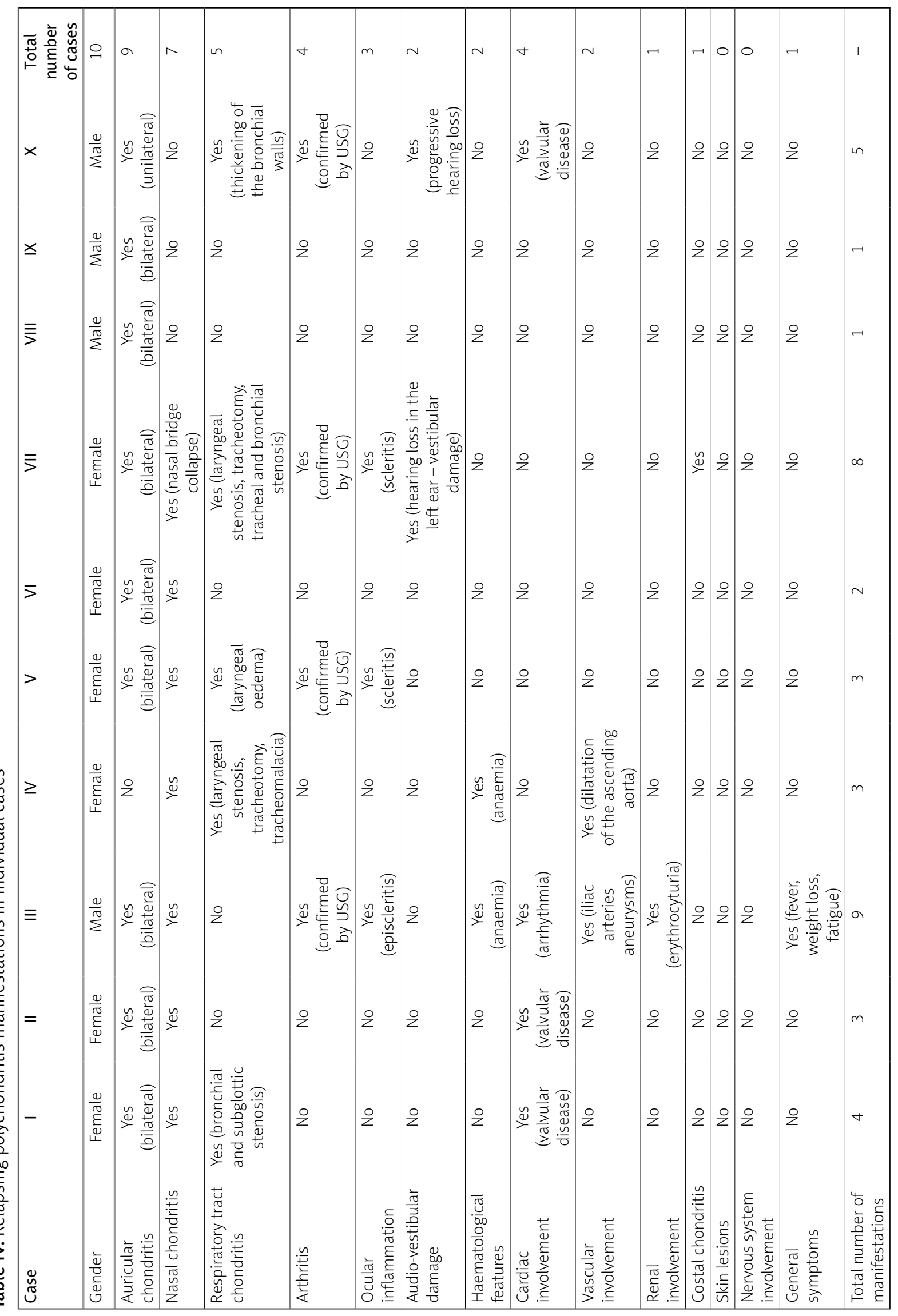


Table V. Selected laboratory results in individual cases

\begin{tabular}{|c|c|c|c|c|c|}
\hline Case/Gender & $\begin{array}{c}\text { ESR } \\
\mathrm{n}: 0-10(\mathrm{~mm} / \mathrm{h})\end{array}$ & $\begin{array}{c}\text { CRP } \\
\mathrm{n}: 0-5(\mathrm{mg} / \mathrm{l})\end{array}$ & $\begin{array}{c}\mathrm{Hb} \\
\mathrm{n}: \mathrm{F}: 12-16, \\
\mathrm{M}: 14-18(\mathrm{~g} / \mathrm{dl})\end{array}$ & $\begin{array}{c}\text { ANA } \\
\mathrm{n}:<1: 100\end{array}$ & $\begin{array}{c}\text { ANCA } \\
\mathrm{n} \text { : negative }\end{array}$ \\
\hline I/Female & 28 & 7.46 & 14.0 & Negative & Negative \\
\hline II/Female & 14 & 1.39 & 13.4 & Negative & Negative \\
\hline III/Male & 124 & 128.0 & 9.5 & $\begin{array}{l}\text { Positive } 1: 320 \\
\text { (ENA negative) }\end{array}$ & Negative \\
\hline IV/Female & 11 & 0.61 & 10.1 & Negative & Negative \\
\hline V/Female & 9 & 0.34 & 13.6 & $\begin{array}{l}\text { Positive } 1: 320 \\
\text { (ENA negative) }\end{array}$ & Negative \\
\hline IV/Female & 15 & 0.45 & 14.6 & $\begin{array}{c}\text { Positive } 1: 320 \\
\text { SSA+++ }\end{array}$ & Negative \\
\hline VII/Female & ND & 0.39 & 12.8 & Negative & Negative \\
\hline VIII/Male & 4 & 1,73 & 16.7 & Negative & Negative \\
\hline IX/Male & 17 & 3.3 & 13.7 & $\begin{array}{l}\text { Positive } 1: 320 \\
\text { (ENA negative) }\end{array}$ & Negative \\
\hline X/Male & 7 & 1.58 & 13.9 & Negative & Negative \\
\hline
\end{tabular}

ESR - erythrocyte sedimentation rate; CRP - C-reactive protein; $\mathrm{Hb}$ - haemoglobin; ANA - positive antinuclear antibodies; ENA - extractable nuclear antigens; ANCA - antineutrophil cytoplasmic antibody; ND - no data.

Laboratory results (selected parameters are shown in Table V), such as levels of inflammatory markers, were generally normal or moderately elevated. Only one patient with general symptoms had a significantly elevated erythrocyte sedimentation rate (ESR) and concentration of C-reactive protein (CRP). Positive antinuclear antibodies (ANA) were found in four cases (40\%) in a titre of $1: 320$.

All patients received standard therapy with steroidal treatment in $90 \%$ of cases; one patient was treated with Dapsone. The doses of prednisone ranged from $10 \mathrm{mg} /$ day to $1 \mathrm{mg} / \mathrm{kg} /$ day depending on clinical manifestations. A good response was observed in $80 \%$ $(n=8)$ of cases. In two cases with laryngeal stenosis without a good response to steroids, prednisone was used in doses of $30 \mathrm{mg} /$ day and $75 \mathrm{mg} /$ day (with periodic pulses of methylprednisolone at a dose of $500 \mathrm{mg} /$ day), respectively.

\section{Discussion}

\section{Relapsing polychondritis incidence, age at the time of first symptoms, and diagnosis}

The average age at the onset of the first symptoms in our group was higher than that reported in the study by Dion et al. [10], in which it was $43.5 \pm 15$ years for men and $47 \pm 15$ years for women, but it was similar to one established in the Hazra et al. [6] study from 2015 performed in large group of 117 RP patients. The difference may result from the different sizes of the studied groups.

The delay from the time of the first symptom to the diagnosis was on average one year (and up to 25 years) in the study from Dion et al. [10] and 1.9 years in the study from Hazra et al. In our research, the average delay was 1.7 years, ranging from 2 months to 4.8 years, and was similar to the delay observed by Hazra et al. [6].

Establishing the time of the first manifestation of RP is easier when the disease starts with a typical symptom such as ear chondritis. In our patients with auricular chondritis, the average delay of the diagnosis was noticeably shorter than in cases with less characteristic initial manifestations. It is clear that the appearance of the typical symptom of red ear (painful oedema and redness of the pinna in the cartilaginous part but not in the cartilage-less earlobe) raises the suspicion of RP and shortens the diagnostic process.

\section{Ear and nose manifestations}

Red ear is the presenting symptom of disease in 20-41\% of cases $[3,10]$. Although this symptom suggests the diagnosis of RP, often other causes such as infection, insect bite, and allergic dermatitis are suspected at first, and so an initial misdiagnosis is quite common.

Auricular chondritis was present in $90 \%$ of our patients in the course of the disease, similarly to data from the literature (85-95\%) [1, 3] and was the most frequent manifestation of RP. Onset of inflammation is abrupt, mono- or bilateral. The cartilaginous part of the pinna is red, painful, and swollen. The ear lobe, which lacks cartilage, remains intact. As a consequence of recurrent episodes of inflammation, the cartilage is damaged and replaced by fibrous connective tissue. The pinna loses its 
normal morphology and becomes floppy and nodular or looks like "cauliflower".

While the external ear involvement is the most common clinical feature of RP, abnormal audio-vestibular findings are observed in $40 \%$ of cases [11]. Unilateral or bilateral conductive and sensorineural hearing loss was observed in up to $46 \%$ of patients with RP [3]. Conductive type hearing loss may be related to the oedema of the external ear canal or the eustachian tube. Closure of the external auditory meatus may lead to serious otitis media. Inflammation of vestibular structures or vasculitis of the internal auditory artery may cause sensorineural type hearing loss. In our study, hearing impairment was observed in two patients, including one patient with hearing loss in one ear and disturbances of balance.

The incidence of nasal cartilage inflammation in RP patients, another laryngological symptom of the disease, varies across different regions, from $10 \%$ in Brazil [12], 20-35\% in the USA, 56-63\% in Germany and France, and up to $81 \%$ in India [3, 13-15]. It manifests as a stuffed nose, tenderness or pain located in the nasa bridge, and, rarely, epistaxis. Progressive inflammation leads to cartilage damage, which may result in the flattening of the nasal bridge and a "saddle nose" deformity. Such a deformity is observed more frequently in female patients and in those under 50 years of age [1].

While Michet [9] described the occurrence of the saddle nose deformity in $29 \%$ of patients, in our study it was found in only 10\% (one woman).

Nevertheless, nasal chondritis occurred in $70 \%$ of patients and was the second most common manifestation of RP in our study. In one case, it was the cause of a prior hospitalisation at the Department of Otolaryngology. However, a diagnosis of RP was not established at that time, and only a retrospective analysis of the course of the disease related to the diagnosis of the auricular chondritis led to the conclusion that previous inflammation of the nasal cartilage was the first symptom of RP. In fact, symptoms such as nasal congestion, nose soreness, or nasal discharge are not characteristic for RP and can be easily taken for infectious or allergic rhinitis or sinusitis.

\section{Airway involvement}

Airway involvement is one of the main causes of morbidity and mortality in RP. Its prevalence is about $50 \%$, and the prevalence of upper airway collapse is $20 \%$. All the cartilaginous parts of the upper and lower airways can be affected [16]. Involvement of the larynx may cause subglottic stenosis. It may manifest with hoarseness, cough, dysphonia, wheezing, stridor, dyspnoea, choking, and tenderness in the anterior part of the neck. Sometimes it has to be treated with emergency tracheosto- my. The involvement of trachea and main bronchi may develop insidiously and may cause fatal respiratory tract collapse. It is more difficult to diagnose, and one should actively search for this complication because it can have few symptoms. It can manifest with dry cough, dyspnoea, and wheezing, and be mistaken for asthma [17]. In worse cases it can progress to respiratory distress and tracheal collapse. Also, the bronchi can be affected, and inflammatory infiltrate of the cartilage and the area around the bronchial wall with consequent destruction and fibrosis of the cartilaginous parts may lead to serious stenosis of the lumen. Diagnostic tools to assess respiratory tract involvement are respiratory function tests, chest radiograph, or better dynamic chest $\mathrm{CT}$ - during inspiration and expiration, to observe the collapse of bronchial or tracheal wall, which occurs due to tracheobronchomalacia [18]. In the early stage of the disease, CT shows thickening of the airway wall and cartilage attenuation, and in later stages focal or diffuse luminal narrowing, which is caused by cartilage destruction and fibrosis.

Bronchoscopy may confirm the mucosal inflammation, airway stenosis, or tracheobronchomalacia, but it has to be performed with caution because of the fragility of airway wall and risk of perforation [19]. Sometimes, respiratory tract involvement demands reconstruction surgery, which is also associated with serious risk because inflamed tissues may collapse during the operating procedure, and it may be complicated by infection. In our patients, involvement of the respiratory tract occurred in $50 \%$ and airways collapse due to laryngeal stenosis occurred in $20 \%$ of patients, which is comparable to the general prevalence of these complications in RP. Isolated chondritis of the larynx or trachea may also be observed. It is especially challenging when chondritis or the respiratory tract is present and it is an isolated feature of RP. In three of our patients, airways involvement was the first symptom of the disease. In one of them it was made as late as after 58 months, in another it was 45 months later, and in a third it was 15 months later. Two patients required emergency tracheostomy. In both of them, the rest of the tracheobronchial tree was gradually involved; one patient later developed critical stenosis of trachea and bronchi, the other - tracheomalacia. In another three of our patients, the airway involvement was diagnosed by imaging methods - mostly CT of the neck and chest. One patient had stenosis of the right bronchus, one had thickening on the bronchial wall on CT, and one had laryngeal oedema revealed in endoscopy. In two of them, the diagnosis was made earlier, thanks to the concomitant features of cartilage inflammation of other sites.

Our series and other reports show that in rare cases airway involvement in RP may precede inflammation 
in other cartilaginous structures. Such a situation may cause diagnostic difficulties and delay diagnosis.

Because RP is a very rare disease, it is not always suspected in patients with subglottic stenosis, especially without other features of connective tissue disease and without visible cartilage involvement in other sites. Differential diagnosis as granulomatous polyangiitis should be considered, which is also a rare disease but still more common than RP.

Respiratory tract involvement is associated with poor prognosis in RP patients. Strictures, mucosal oedema, and cartilage collapse can lead to fatal airway obstruction, which requires tracheostomy and is a poor prognostic sign. Tracheobronchomalacia may need airway stenting. However, the risk of surgical procedure on the inflamed and fragile tissue is high.

When the patient has other signs of RP, such as auricular or nasal cartilage inflammation, the diagnosis is obvious, and one should actively search for airway involvement.

\section{Ocular manifestations}

Ocular manifestations of RP are common and were present in $30 \%$ of cases in our study (episcleritis $n=1$, scleritis $n=2$ ) and in up to $60 \%$ of patients, according to the literature [20].

In a cohort study performed by the Mayo Clinic on 112 patients with RP, 21 (18.75\%) of them had eye symptoms at the onset of the disease and 57 (50.89\%) were diagnosed with ocular involvement later on [21].

All structures of the eye may be involved in the course of RP. Common early findings include episcleritis, scleritis, conjunctivitis, iridocyclitis, chorioretinitis, corneal infiltrates, and lid oedema [21].

Scleritis may be the initial manifestation of RP and has some typical characteristics when connected with RP. Sainz-de-la-Maza et al. [22], in a retrospective analysis of 13 RP patients diagnosed with scleritis, compared 113 patients with other autoimmune diseases and showed that scleritis in RP patients was more often bilateral $(p=0.001)$, necrotising $(23.1 \% ; p=0.02)$, recurrent $(p=0.001)$, and associated with decreased vision $(p=0.012)$. A significant proportion of RP patients from that study $(9 / 13,69.2 \%)$ had one or more other autoimmune conditions, which on average preceded RP by nine years (between two and 21 years).

Uveitis is a less common and more serious complication of RP. It presents as red eye, ocular pain, and decreased vision. This condition may be associated with keratitis, macular oedema, retinal haemorrhages, and retinal vasculitis [20]. In the course of RP, uveitis is often bilateral and recurrent, and if left untreated it may lead to permanent vision loss.
Less frequently reported are exophthalmos associated with an orbital tumour or pseudotumor and optic neuritis, accompanied by orbital periostitis on MRI. Late ocular complications include: cataract, glaucoma, exudative retinal detachment, and blindness.

\section{Arthritis}

According to a 2016 study from Mathian et al. [2], arthritis in the course of the disease occurs in $38.8 \%$ of patients, compared to $51-85 \%$ described in previous publications. In our study, arthritis confirmed by joint ultrasound examination was found in $30 \%$ of patients. In one case (10\%), arthritis was the first manifestation of the disease. The delay between this symptom and the diagnosis was four years. Arthritis in the course of RP is seronegative, and if it is not associated with cartilage involvement, the recognition of RP only on its basis is not possible, according to the applicable criteria.

\section{Cardiovascular involvement}

In a large cohort study performed in Japan on 239 RP patients, the prevalence of cardiac involvement was $7.1 \%$, compared to $6-23 \%$ worldwide [23]. In the Japanese cohort, heart manifestations were more frequent in males and older patients $(p<0.01)$. The mean age of patients with cardiac RP was 72 years, while the mean age of the onset of symptoms in these patients was 65 years. In comparison to RP patients without cardiac symptoms, heart involvement in RP patients was connected with external ear manifestations (100\% vs. $76 \%$ ), renal symptoms (35\% vs. $6.7 \%)$, central nervous system complications (29\% vs. $8.1 \%)$, and an increased death rate $35 \%$ vs. $9.2 \%)$. In the cited study, the causes of mortality in cardiac RP patients included acute myocardial infarction, recurrent angina pectoris, heart failure, cerebral haemorrhage, and pneumonia [23]. Other fatal outcomes described in the literature include complete heart block, aortic valve rupture, and acute aortic insufficiency.

Late cardiovascular RP complications include atrioventricular conduction disturbances, pericarditis, valvulitis, and large- and medium-sized vasculitis, accompanied by the aneurysm formation. According to the literature, $4 \%$ to $7 \%$ of RP patients develop aneurysmal disease. In the presented analysis, one patient had bilateral aneurysms of the common iliac arteries. This seems to be an extremely rare finding because there has been only one case report on an aneurysm with a similar location in the course of RP [24]. Other unusual aneurysm sites include pulmonary arteries, and intracranial and renal locations. The most common aneurysm site in patients with RP is the aorta, and in one study it was involved in as many as $6.4 \%$ of RP patients [25]. In our 
study, only one elderly female patient had an abnormally wide aorta, not yet classified as an aneurysm, three patients (30\%) had mild valve defects, and a male patient - one with iliac arteries aneurysms - had a life-threatening arrhythmia.

\section{Renal manifestations}

According to Rednic et al. [14], the existence of kidney involvement in the course of RP is a controversial issue, probably due to a possible misdiagnosis. In a previous study from Chang-Miller et al. [26], 29 out of 129 RP patients treated at the Mayo Clinic had renal symptoms, but biopsy was positive in less than $10 \%$ of patients with suspicion of renal RP.

In our case series, renal abnormalities presented by mild erythrocyturia were limited to one patient with cardiovascular complications of RP.

\section{Haematological symptoms}

An estimated $4-8 \%$ of RP patients have myelodysplastic syndrome (MDS) [6, 10]. There are no cases of MDS in our study. In $20 \%$ of our patients, clinically significant anaemia was diagnosed.

\section{Cutaneous, mucosal, and central nervous system manifestations}

The most common skin and mucosal symptoms in the course of RP reported in the literature were erythema, oral aphthae, and superficial phlebitis. Less frequent manifestations included erythema multiforme, angioneurotic oedema, pustular skin disease, urticaria, purpura, haemorrhagic blushes, and erythema nodosum.

According to the literature, skin lesions occur in $1 / 3$ of patients [2]. However, they were not observed in the studied group. The absence of reports of skin changes may be due to their paroxysmal nature and patients not considering them as related to the underlying condition.

Also, we did not notice nervous system involvement, occurring only rarely (in 3\% of patients, according to the literature) in the course of RP. It may be manifested with headaches, memory disturbances, paraesthesia, and cranial nerve neuropathies, probably due to cerebral vasculitis. Also, about 20 cases of RP patients with a mild form of meningitis and/or encephalitis have been described [27].

\section{Laboratory findings}

There are no specific laboratory tests characteristic for RP. Elevated ESR and CRP may be detected during the acute onset of RP, but more than $10 \%$ of patients have a normal CRP level even during an RP flare [2]. In contrast to results from Chuah et al. [28], who observed elevated ESR in $80 \%$ and CRP in $50 \%$ of their study, only $10 \%$ of cases from our study presented significantly increased levels of inflammatory markers.

In an analysis of 111 RP patients from Piette et al. [29], ANA titre $>1 / 100$ was found in only $9 \%$ of cases. McAdam et al. [7] found positive ANA in four of their 18 patients (22\%). In the present study, $40 \%$ of RP patients with no coexisting connective tissue disorder were ANA-positive.

\section{The clinical phenotypes of relapsing polychondritis}

Analysing the manifestations of RP in individual cases, we observed various forms of the disease, from a mild course with the inflammation of the pinna $(n=2)$ without damage to other organs, to a severe multi-systemic course with vital organ damage.

Dion et al. [10] divided a group of 142 RP patients into three groups with diverse clinical phenotypes. The first group (9\%) consisted of patients with the most severe course of the disease, referred to as a haematological phenotype, because many of them had MDS (83\%). In these patients, other common features included skin lesions (92\%), general symptoms (83\%), and heart involvement (58\%), without respiratory tract changes. The second group of patients (26\%) was characterised as the respiratory phenotype with laryngeal or tracheal and bronchial involvement, and the third group, the largest (65\%), as the mild phenotype with few symptoms.

According to the classification from Dion et al., in our study, one patient (10\%) represented a haematological phenotype, presenting with anaemia, general symptoms, high levels of inflammatory parameters, arrhythmia, and iliac artery aneurysms (in total nine RP manifestations) but no MDS.

Five patients in our study (50\%) represented a respiratory phenotype with airway cartilage involvement, including two patients with life-threatening laryngeal obstruction requiring tracheostomy. Four patients (40\%) could be classified as a mild phenotype with the inflammation of the pinna as the main manifestation of the disease.

The phenotype division according to Dion et al. [10] may be useful for determining the prognosis and deciding on intensity of treatment. However, as cardiac and cardiovascular complications are associated with highest mortality among the RP patients, we would suggest the fourth, cardiovascular phenotype, be included in RP patients' phenotypical classification.

\section{The role of diagnostic criteria}

The classification criteria for RP by McAdam [7], Damiani and Levine [8], or Mitchet et al. [9] are used in 
order to make the diagnosis of RP. However, there are no clinical practice guidelines, nor randomised clinical studies available for RP in the literature review, because there are no specific laboratory markers that could be used for diagnosis or evaluation of the disease activity.

In our study, the RP diagnosis was confirmed in 50\% of cases ( $n=5)$ according to McAdam's criteria, in $80 \%$ of cases $(n=8)$ according to the criteria of Damiani et al., and in $80 \%$ of cases according to Mitchet's criteria, including two cases of patients who did not meet the McAdam's criteria and one patient who did not meet either McAdam's or Damiani and Levine's criteria. One patient met only Mitchet's criteria, and another patient met only Damiani and Levine's criteria.

Modified Michet's criteria are the most commonly used worldwide. However, no set of criteria has been yet validated due to the scarcity of data on their sensitivity and specificity. The available information on their sensitivity comes from one small cohort study. In a retrospective analysis of 18 patients with a diagnosis of RP performed at the Berlin University Centre, the best sensitivity (88.9\%) characterised the Damiani and Levine criteria, versus Michet's (66.7\%) and McAdam's (50\%). The sensitivity of Michet's criteria was improved to $88.9 \%$ after modification [30]. The specificity of the criteria is yet to be established.

McAdam's criteria may be helpful in the case of longer disease duration and with at least three different manifestations. Auricular chondritis, in these criteria, is important but only when bilateral, and hearing loss together with balance disturbances is considered as one symptom.

A careful analysis of the manifestations of the disease allows a diagnosis to be established without biopsy in $50 \%$ of cases. The cartilage biopsy may be useful in patients with the mild phenotype and few symptoms, such as in the case of our patient who presented with isolated auricular chondritis.

\section{Conclusions}

Relapsing polychondritis is a rare disease, which causes difficulties in diagnosis due to the non-simultaneous occurrence of symptoms. During the onset, various organs may be involved, and only analysis of the entire medical history leads to proper diagnosis. The approach to the RP problem should not be focused only on making a diagnosis but also on detection of latent and potentially life-threatening manifestations such as aneurysms of large vessels, arrhythmias, heart valve defects, and narrowing of the airways.

Relapsing polychondritis should also be considered in differential diagnosis of respiratory tract narrowings. The increased awareness of the disease among physicians, both rheumatologists and specialists outside the field of rheumatology, including general practitioners, may lead to early diagnosis and treatment. Taking into account data from the literature and the presented analysis, we suggest that it is very useful to apply the three sets of criteria simultaneously in the RP diagnostic process.

The authors declare no conflict of interest.

\section{References}

1. Trentham DE, Le CH. Relapsing Polychondritis. Ann Intern Med 1998; 129: 114-122.

2. Mathian A, Miyara M, Cohen-Aubart F, et al. Relapsing polychondritis: A 2016 update on clinical features, diagnostic tools, treatment and biological drug use. Best Pract Res Clin Rheumatol 2016; 30: 316-333.

3. Borgia F, Giuffrida R, Guarneri F, Cannavò SP. Relapsing Polychondritis: An Updated Review. Biomedicines 2018; 6: pii: E84.

4. Horváth A, Páll N, Molnár K, et al. A nationwide study of the epidemiology of relapsing polychondritis. Clin Epidemiol 2016; 8: 211-230.

5. Kent PD, Michet CJ, Luthra HS. Relapsing polychondritis. Curr Opin Rheumatol 2004; 16: 56-61.

6. Hazra N, Dregan A, Charlton J, et al. Incidence and mortality of relapsing polychondritis in the UK: a population-based cohort study. Rheumatology (Oxford) 2015; 54: 2181-2187.

7. McAdam LP, O'Hanlan MA, Bluestone R, Pearson CM. Relapsing polychondritis: prospective study of 23 patients and a review of the literature. Medicine (Baltimore) 1976; 55: 193-215.

8. Damiani JM, Levine HL. Relapsing polychondritis - report of ten cases. Laryngoscope 1979; 89: 929-946.

9. Michet CJ, McKenna CH, Luthra HS, O'Fallon WM. Relapsing polychondritis. Survival and predictive role of early disease manifestations. Ann Intern Med 1986; 104: 74-78.

10. Dion J, Costedoat-Chalumeau N, Sène D, et al. Relapsing Polychondritis Can Be Characterized by Three Different Clinical Phenotypes: Analysis of a Recent Series of 142 Patients. Arthritis Rheumatol 2016; 68: 2992-3001.

11. Puéchal X, Terrier B, Mouthon L, et al. Relapsing polychondritis. Joint Bone Spine 2014; 81: 118-124.

12. Pallo PAO, Levy-Neto M, Pereira RMR, Shinjo SK. Relapsing polychondritis: prevalence of cardiovascular diseases and its risk factors, and general disease features according to gender. Rev Bras Reumatol 2017; 57: 338-345.

13. Mathew SD, Battafarano DF, Morris MJ. Relapsing Polychondritis in the Department of Defense Population and Review of the Literature. Semin Arthritis Rheum 2012; 42: 70-83.

14. Rednic S, Damian L, Talarico R, et al. Relapsing polychondritis: state of the art on clinical practice guidelines. RMD open 2018; 4 (Suppl 1): e000788.

15. Sharma A, Bambery P, Wanchu A, et al. Relapsing polychondritis in North India: a report of 10 patients. Scand J Rheumatol 2007; 36: 462-465.

16. Ernst A Rafeq S, Boiselle P, et al. Relapsing polychondritis and airway involvement. Chest 2009; 135: 1024-1030. 
17. Mohammad A, Ambrose N, Tuohy $M$, et al. Relapsing polychondritis: reversible airway obstruction or asthma. Clin Exp Rheumatol 2008; 26: 938-940.

18. Mohsenifar Z, Tashkin DP, Carson SA, Bellamy PE. Pulmonary function in patients with relapsing polychondritis. Chest 1982 81: 711717.

19. Tillie-Leblond I, Wallaert B, Leblond D, et al Respiratory involvement in relapsing polychondritis. Clinical, functional, endoscopic, and radiographic evaluations. Medicine (Baltimore) 1998; 77: 168-176.

20. Karim A, Allali F, Tachfouti S, et al. Bilateral uveitis in relapsing polychondritis. A case report. J Fr Ophtalmol 2005; 28: 530532.

21. Isaak BL, Liesegang TJ, Michet CJ. Ocular and systemic findings in relapsing polychondritis. Ophthalmology 1986; 93 681-689.

22. Sainz-de-la-Maza M, Molina N, Gonzalez-Gonzalez LA, et al. Scleritis associated with relapsing polychondritis. $\mathrm{Br} J \mathrm{Oph}$ thalmol 2016; 100: 1290-1294.

23. Shimizu J, Oka H, Yamano Y, et al. Cardiac involvement in relapsing polychondritis in Japan. Rheumatology 2015; 55: 583-584.
24. Joyeux A, Vavdin F, Caudine M, Thevenet A. Iliac-femoral artery involvement in relapsing polychondritis. J Mal Vasc 1984; 9: 207-210.

25. Le Besnerais M, Arnaud L, Boutémy J, et al. Aortic involvement in relapsing polychondritis. Joint Bone Spine 2018; 85: 345-351.

26. Chang-Miller A, Okamura $M$, Torres VE, et al. Renal involvement in relapsing polychondritis. Medicine (Baltimore) 1987; 66: 202-217.

27. Nara M, Komatsuda A, Togashi M, Wakui H. Relapsing Polychondritis with Encephalitis: A Case Report and Literature Review. Intern Med 2015; 54: 231-234.

28. Chuah D, Yu T, Chuah TY, Lui NL. Relapsing polychondritis in Singapore: a case series and review of literature. Singapore Med J 2017; 58: 201-205.

29. Piette JC, El-Rassi R, Amoura Z. Antinuclear antibodies in relapsing polychondritis. Ann Rheum Dis 1999; 58: 656-657.

30. Rose T Schneider U, Bertolo M, et al. Observational study and brief analysis of diagnostic criteria in relapsing polychondritis. Rheumatol Int 2018; 38: 2095-2101. 